\title{
Proceeding
}

Supplementary Issue: Summer Conferences of Sports Science. First International Conference in Iraq on Sport for Peace, 4 April 2019. Baghdad Science Institute, Baghdad, Iraq.

\section{Influence of pantocrin and maral root on processes of adaptation of the powerlifter organism}

\author{
RUZEL KHABIBULLIN ,AYGUL BAKIROVA, ILMIR KHABIBULLIN, RAFAEL RAKHMATULLIN, EL'MIRA \\ AHMADULLINA \\ Federal State Budgetary Educational Institution of Higher Education "Bashkir State Agrarian University", \\ UFA, Russian Federation
}

\begin{abstract}
The aim of our research was to study the adaptogenic properties of maral root and pantocrin and the possibility of their application in the practice of sports training of powerlifters in the preparatory period. In studies with students and undergraduates of the Bashkir Agrarian University, adaptive possibilities and effective norms for the use of these adaptogens during periods of high physical exertion on all muscle groups were established. It has been revealed that the use of tinctures of pantocrin and maral root by parenteral administration enhances the endurance of athletes, increases strength indicators, and shortens the recovery period after training and competition. The beneficial effect of these drugs on the nervous system was established, in particular, increased mobility and balance of nervous processes, which led to an improvement in the assimilation of complex technical actions by athletes. At the physiological level, a slight increase in haemoglobin level and an increase in the number of red blood cells were revealed. All this was accompanied by an improvement in the indicators of the main indicator of the functional state of the body - the cardiorespiratory system. In particular, the peroral administration of tinctures of pantocrin and maral root in certain doses reduced the heart rate and contributed to the rapid restoration of blood pressure and respiratory rate after exercise. General conclusion: the use of tinctures of pantocrin and maral root helps to increase the functional state of the body and increase the strength indicators of athletes. Keywords: Pantocrin; Sports training; Human sport; Athletes.

Cite this article as:

Khabibullin, R., Bakirova, A., Khabibullin, I., Rakhmatullin, R., \& Ahmadullina, E. (2019). Influence of pantocrin and maral root on processes of adaptation of the powerlifter organism. Journal of Human Sport and Exercise, 14(5proc), S2076-S2083. doi:https://doi.org/10.14198/jhse.2019.14.Proc5.28

Corresponding author. Federal State Budgetary Educational Institution of Higher Education "Bashkir State Agrarian University", UFA, Russian Federation.

E-mail: ruzel_khabibullin@rambler.ru

Supplementary Issue: Summer Conferences of Sports Science. First International Conference in Iraq on Sport for Peace, 4 April 2019. Baghdad Science Institute, Baghdad, Iraq.

JOURNAL OF HUMAN SPORT \& EXERCISE ISSN 1988-5202

(c) Faculty of Education. University of Alicante

doi:10.14198/jhse.2019.14.Proc5.28
\end{abstract}




\section{INTRODUCTION}

We agree with Banting, L. K., Pushkarev, V. P., Cieszczyk, P., Zarebska, A., Maciejewska-Karlowska, A., Sawczuk, M. A., .. \& Pushkareva, Y. E. and Ogulchansky, V.A., \& Sedykh, N.V., Sheiko, B.I., \& Sarychev, K.I., Abbasi, M., \& Zare, A. and Ayalew, Y. (Banting et al., 2015; Ogulchansky \& Sedykh, 2017; Sheiko \& Sarychev, 2017; Abbasi \& Zare, 2016; Ayalew, 2017), confirming the relevance of the search for natural stimulants to increase the athlete's working capacity and stress resistance in conditions of intense training and competition. The effectiveness of the use of natural mild stimulants to increase the functional capabilities of the body was quite convincingly substantiated in a study of (Kreider et al, 2009), who observed athletes whose nutrition included natural adaptogens. The beneficial effects of such drugs on enhancing the biomechanical work of muscles are also demonstrated in (Samsonova et al, 2018). One of the important tasks facing trainers, sports doctors and athletes themselves is the search for tools that accelerate the recovery processes in the body, enhancing its functional capabilities. To optimize the biological processes in the athlete's body, according to Nikolaev, P.P., \& Nikolaeva, I.V. and Voisin, S., Guilherme, JPF, Yan, X., Pushkarev, VP, Cieszczyk, P., Massidda, M., ... \& Maciejewska, A. (Voisin et al., 2016; Nikolaev \& Nikolaeva, 2017 ) it is necessary to develop a system for the restoration of morphological and physiological functions body after heavy physical exertion. We are convinced that the search for funds for this should be carried out taking into account the following three requirements: a) natural adaptogens should not be doping; b) must not cause damage to the health of the athlete; c) must have a significant raw material resource, to be readily available for purchase. The latter requirement is caused by the problem of the exhaustion of wild stocks of such traditional phytoadaptogens as the root of Ginseng and Aralia of Manchurian, fruits and seeds of Schisandra, Eleutrococcus, which is the reason for the search for other adaptogens of plant and animal origin (Matsubara \& Yoshida, 2018). In this regard, in order to increase the functional capabilities of the athlete's body, to achieve higher athletic performance, and to minimize the negative consequences of large physical exertion, we propose using biological active substances - adaptogens of animal and plant origin - pantocrin and maral root in the training process. This article, which presents the results of a study of this topic, is the continuation of our research in this area, published in articles by Khabibullin, R.M., Ismagilova, E.R., Khabibullin, I.M; Khabibullin, R.M., Ismagilova, E.R., Bakirova, A.U. (Khabibullin et al., 2018; 2018b). Thus, the aim of the study is to study the effect on the body of a powerlifter athlete of biologically active substances such as maral root and pantocrin against the background of great physical exertion.

\section{RESEARCH OBJECTIVES}

To study the degree of influence of tinctures of maral root and pantocrin on a) the development of power indicators of powerlifters; b) adaptation of the body to great physical exertion; c) indicators of the cardiorespiratory and nervous system.

\section{MATERIALS AND METHODS}

The methodological basis of the study is the principles of sports adaptology, first of all, the principle of the unity of the organism and the environment, adaptation, as well as the general principles of theoretical and applied research presented in the works: Gabitov, I.I. Badretdinov, I.D. Mudarisov S.G., Khasanov, E.R. Lukmanov, R.L. Nasyrov, R.R. Tuktarov, M.F. Atnagulov, D.T. Timeriashev I.A. and Pavlenko, V.A. and Lubova T.N., Islamgulov D.R., Ismagilov K.R., Ismagilov, R.R., Mukhametshin, A.M., Alimgafarov, R.R., Enikiev, R.I., Bakirova, A.U., Kamilanov, A.A .., \& Lebedeva, O.Yu. and Shafikova, L.R., \& Greb, A.V. (Lubova et al., 2017; Gabitov et al., 2018; Shafikova \& Greb, 2018). The study used traditional empirical methods: observation, experiment, measurement, description, modern methods of blood testing - model, physiological, 
morphological, statistical and generalizing methods adopted in the study of the functional characteristics of the powerlifter organism used in the study of Chesnokov, AV, \& Fenzel, AD and Shafikova, L.R., \& Greb, A.V. (Chesnokov \& Fenzel, 2016; Shafikova \& Greb, 2018). The application of these methods allowed both to obtain important empirical material about the influence of the studied adaptogens on the athletic performance and functional characteristics of the athlete's body, and also served as a good help for improving the system of training powerlifters in the preparatory period of training associated with heavy physical exertion. The studies were conducted with the participation of 21 male athlete-powerlifters aged 17-22 years old, studying in the undergraduate and graduate programs of the Bashkir State Agrarian University. The participants had the 1,2 and 3 sports categories. The participation of athletes in the experiment was carried out on a voluntary basis. The course of the experiment:

The participants were divided into 3 groups: a) control group (7 people); b) experimental group 1 (7 people); c) experimental group 2 (7 people). Both drugs under consideration were administered to groups 1 and 2 by ingestion (oral). In the experimental group 1, participants were given tincture of maral root according to the instructions ( 25 drops) for 28 days, in experimental group 2 they were given tincture of pantocrin according to the instructions ( 25 drops) for 28 days. The participants in the control group were given distilled water (25 drops) for 28 days. All preparations were given once a day. As in the studies of Nikolaev, P.P., \& Nikolaeva, I.V. and Yakubenko, Ja. E. (Yakubenko, 2016; Nikolaev \& Nikolaeva, 2017b) at the initial stage (1-4 days of the experiment), the participants were examined for heart rate (HR), blood pressure (BP) indicators, on the first and last day of the experiment, they performed a general blood test (white blood cell, red blood cell count, hemoglobin). The erythrocyte sedimentation rate (ESR) was also measured. The blood sampling and analysis was carried out in the laboratory of the Republican Sports and Health Center (Ufa, 1 Blucher St.). The study was conducted in 2 stages: the initial stage (1-4 days of the experiment) and the final stage (2528 days of the experiment).

\section{ANALYSIS AND RESULTS}

The heart rate $(\mathrm{HR})$ at the beginning and at the end of the experiment made it possible to establish its decrease in athletes in both the control and experimental groups (Table 1).

Table 1. Heart rate indicators in young men at the beginning and at the end of the training cycle.

\begin{tabular}{|c|c|c|c|c|}
\hline \multirow{2}{*}{ № } & \multirow{2}{*}{ Group of athlets } & \multirow{2}{*}{$n$} & \multicolumn{2}{|c|}{$\mathrm{HR}$ (per minute) } \\
\hline & & & At the beginning & Ater 28 days \\
\hline 1 & Control group & 5 & $67.3 \pm 5.4$ & $66.0 \pm 4.1$ \\
\hline 2 & Experimental 1 & 5 & $69.1 \pm 4.9^{*}$ & $65.1 \pm 3.3^{* *}$ \\
\hline 3 & Experimental 2 & 5 & $68.9 \pm 5.8$ & $64.7 \pm 4.3^{*}$ \\
\hline
\end{tabular}

The table shows that with the participants in the control group, the indicator decreased slightly (from 67.3 to 66.0 ). In our opinion, this is due to the natural adaptation of the cardiovascular system to significant training loads within a month. In athletes of the experimental group No. 1, who took tincture of maral root, the indicator changed to a greater extent: the decrease is from 69.1 to 65.1 . Approximately the same dynamics was observed in experimental group No. 2, the participants of which took pantocrin tincture. The indicator in the 2 group decreased on average by 4.2. The reasons for the change in heart rate as a result of the experiment can be explained by two factors: a) natural adaptation of the body to significant physical activity within 4 weeks; $b$ ) the use of natural adaptogens of maral root and pantocrin. The results of the experiment suggest a noticeable effect of these drugs on heart rate. Along with the study of the dynamics of heart rate, the content of the experiment also included indicators of blood pressure (BP), as an important indicator of the state of 
the cardiovascular system. The experimental conditions (participants, groups, study period, drugs, place) did not change. The experimental results are presented in Table 2.

Table 2. Indicators of blood pressure (BP) in athletes in the study period.

\begin{tabular}{|l|l|l|l|l|}
\hline \multirow{2}{*}{$№$} & \multirow{2}{*}{$\mathrm{n}$} & & \multicolumn{2}{|c|}{$\mathrm{BP}$} \\
\cline { 4 - 6 } 1 & Control & 5 & $1-4$ day & $25-28$ day \\
\hline 2 & Experimental 1 & 5 & $122.2 \pm 3.7$ & $121.0 \pm 4.2$ \\
$75.2 \pm 2.33$ & $73.8 \pm 3.7$ \\
\hline 3 & Experimental 2 & 5 & $123.6 \pm 5.07^{*}$ & $119.0 \pm 6.7^{* *}$ \\
& & 5 & $69.8 \pm 4.51^{*}$ & $70.3 \pm 4.2^{* *}$ \\
\hline
\end{tabular}

The table shows that as a result of four weeks of the training process, there is a slight decrease in blood pressure in athletes of all three groups, regardless of the use of experimental adaptogens. Such dynamics can be explained by physiological changes in the body during its natural adaptation (alteration) to large training loads. Note that both indicators of heart rate and blood pressure of the subjects were in the range of physiological norms. The most important indicator of the functional state of an athlete's body is the dynamics of changes in blood composition. In a study conducted with the same participants, blood parameters such as a) white blood cell content; b) the content of red blood cells; c) the level of hemoglobin; d) erythrocyte sedimentation rate. Samples for laboratory analysis were taken on the first and last day of the experiment. The results of the study are presented in Table 3.

Table 3. Morphological changes in the blood of powerlifters in the study period.

\begin{tabular}{|c|c|c|c|c|c|}
\hline \multirow{2}{*}{\multicolumn{2}{|c|}{ Groups examined $(n=7)$}} & \multicolumn{4}{|c|}{ Indicators } \\
\hline & & \multirow{2}{*}{$\begin{array}{l}\text { leucocytes, } \\
x 10^{9} / 1 \\
6.13 \pm 0.42\end{array}$} & \multirow{2}{*}{$\begin{array}{l}\text { erithrocytes, } \\
x 10^{12 /} \\
4.88 \pm 0.17\end{array}$} & \multirow{2}{*}{$\begin{array}{l}\text { hemoglobin, } \\
\text { g/l } \\
139.1 \pm 1.75\end{array}$} & \multirow{2}{*}{$\begin{array}{l}\begin{array}{l}\text { ESR, } \\
\mathrm{mm} / \mathrm{h}\end{array} \\
3.85 \pm 0.51\end{array}$} \\
\hline & $1^{\text {st }}$ day & & & & \\
\hline Control & $28^{\text {th }}$ day & $6.41 \pm 0.18$ & $5.06 \pm 0.30$ & $140.2 \pm 1.73$ & $3.87 \pm 0.77$ \\
\hline \multirow{2}{*}{ Experimental 1} & beginning & $6.19 \pm 0.18$ & $4.79 \pm 0.18$ & $138.3 \pm 0.16$ & $4.09 \pm 0.58$ \\
\hline & 28 days & $6.60 \pm 0.21$ & $5.66 \pm 0.23$ & $140.9 \pm 0.77$ & $4.04 \pm 0.66$ \\
\hline \multirow{2}{*}{ Experimental 2} & beginning & $6.11 \pm 0.26$ & $4.80 \pm 0.13$ & $141.1 \pm 0.1$ & $4.97 \pm 0.81$ \\
\hline & 28 days & $6.46 \pm 0.33$ & $5.87 \pm 0.25$ & $144.2 \pm 0.88$ & $5.08 \pm 0.79$ \\
\hline
\end{tabular}

The obtained results of the dynamics of leukocyte blood levels allow us to conclude that taking maral root and pantocrin within 28 days did not lead to noticeable changes. A slight increase in the level of leukocytes can be explained both by the action of the intake of adaptogens and by an increase in the activity and resistance of the body of athletes, its mobility in conditions of significant physical exertion. The changes in red blood cell counts are more noticeable. Their number in the blood of participants in the control and experimental groups on the first day of the experiment was: in the control group $4.88 \pm 0.17 \cdot 10^{12}$ per liter, in the experimental group No. $1-4.79 \pm 0.18 \cdot 10^{12}$ per liter, in the experimental group No. $2-4.80 \pm 0.13 \cdot 10^{12}$ per liter. On day 28 , the indicators increased: in the control group by 0.18 , in experimental group No. 1 - by 0.87 , in experimental group No. 2 - by 1.07. Such a pronounced dynamics of the number of red blood cells is explained not only by lengthy strength exercises, but also by the use by sportsmen of experimental groups of maral root and pantocrin for 4 weeks. Note a more noticeable increase in the number of red blood cells in the blood of participants in experimental group No. 2 who used pantocrin. It is known that the composition of 
red blood cells includes such an iron-containing protein as hemoglobin. Therefore, an increase in the number of red blood cells is accompanied by an increase in the level of hemoglobin in the blood. Since the indicators of the number of red blood cells in athletes who took tinctures of maral root and pantocrin increased markedly, the hemoglobin level in their blood also increased: in experimental group No. 1 the growth was $2.6 \mathrm{~g} / \mathrm{l}$, in experimental group No. 2 - by $3.1 \mathrm{~g} / \mathrm{l}$. Meanwhile, in the control group, this indicator increased only by 1.1 $\mathrm{g} / \mathrm{l}$, which corresponds to a small increase in the number of red blood cells in the blood by a participant in this group. Note that the data we obtained are completely consistent with the results of a study conducted in 2017 by researchers of the Kazan Federal University (Ldokova et al, 2017). Thus, the general blood test in the athletes participating in the experiment showed that the use of tinctures of pantocrin and maral root improves indicators such as heart rate, red blood cell count and hemoglobin level in the blood. Small positive shifts of these indicators among the participants in the control group are explained by natural adaptation processes associated with the adaptation of the cardiovascular and hematopoietic systems of the body to regular physical activity of a forceful nature. The experts in the field of physiology of sports explain the reasons for these positive results in the growth of muscle mass of the heart, its contractile parameters, which ultimately lead to an increase in cardiac output. An important indicator of the functional state of the body, human health is such an indicator as the erythrocyte sedimentation rate (ESR). In the conditions of Earth's gravity for men, the speed from 1 to $10 \mathrm{~mm}$ per hour is considered as the norm (for women - 2-15 mm / h.). An increase in this indicator indicates the presence of an inflammatory process in the body and requires medical intervention. The results of ESR studies in all three groups indicate small changes in this indicator within 4 weeks of observation. So, in the control group, the ESR index increased by $0.02 \mathrm{~mm} / \mathrm{h}$, in the experimental group No. 1 - decreased by $0.05 \mathrm{~mm} / \mathrm{h}$, in the experimental group No. 2 - increased by 0.11 $\mathrm{mm} / \mathrm{h}$. Two conclusions follow from these indicators: a) no traces of inflammation were found in the body of the studied athletes; b) the use of maral root and pantocrin during the training cycle does not reduce or increase the erythrocyte sedimentation rate. Improving the functional state of the body leads to increased athletic performance. Therefore, the next part of our study was the effect of tincture of maral root and pantocrin on such indicators of a powerlifter as squatting with a barbell on the back, bench press lying on a horizontal bench, barbell row. As follows from the work of (Aksenov et al, 2018), (Samsonova et al,2014) and (Sheiko et al, 2013), in the athlete's body sex hormones have the most significant restoring and anabolic properties: in men, androgens (primarily testosterone), in women - progestogens, in both of them - growth hormone (somatotropin). We found that adaptogens had an effect on testosterone production. In particular, in experimental group No. 1, the level of testosterone in the blood rose from $21.68 \mathrm{nmol} / \mathrm{I}$ on the first day of the experiment to 29.55 on day 28 , in experimental group No. 2, from 19.68 to $32.11 \mathrm{nmol} / \mathrm{l}$. Note that a small increase - from 22.41 to $24.44 \mathrm{nmol}$ was recorded in the control group, which is explained by the influence of physical activity on the growth of this indicator. But the results obtained in the experimental groups clearly indicate a stimulating effect of the studied adaptogens on the testosterone production. In particular, the results obtained in the experimental group No. 2, whose members took pantocrin tincture inside, are impressive. Here, the increase was $12.43 \mathrm{nmol} / \mathrm{l}$. To determine the influence of the studied adaptogens on the development of muscle strength on the 6th, 13th, 20th and 27th day, we measured the strength indicators of the subjects in squats, bench presses and barbell pulls. The following results were obtained in the exercise "squat with a barbell on the back": the control group on the 6th day of the experiment showed an average result of $125.0 \pm 13.1 \mathrm{~kg}$, on the 27 th day $-136.6 \pm 14.0 \mathrm{~kg}$ (increase is $11.6 \mathrm{~kg}$ ), in the experimental group No. 1, respectively - from $127.0 \pm 16.1 \mathrm{~kg}$ to $143.0 \pm 16.1 \mathrm{~kg}$ (an increase is $16 \mathrm{~kg}$ ), in the experimental group No. 2 - from $126.5 \pm 15.8$ to $145.0 \pm 14.9$ (an increase is $18.5 \mathrm{~kg}$ ). The following dynamics was observed in the exercise "bench press lying on a horizontal bench": on the 6th day of the experiment: the control group - $100.5 \pm 9.52 \mathrm{~kg}$, on the 27 th day $-100.9 \pm 4.20 \mathrm{~kg}$ (increase $-0.4 \mathrm{~kg}$ ). The experimental group No. $1: 101.0 \pm 14.20 \mathrm{~kg}$ on the 6th day of the experiment and $115.0 \pm 15.00$ at the end of the experiment (an increase is $14 \mathrm{~kg}$ ). The experimental group No. 2: on the 6th day of experiments - 100.8 
$\pm 12.60 \mathrm{~kg}$, on the 27 th day $-116.0 \pm 11.80 \mathrm{~kg}$ (increase $-15.2 \mathrm{~kg}$ ). Thus, athletes taking the studied adaptogens increased their result by an average of $12.7 \%$. We also note that those taking pantocrin have a slightly better result $(0.9 \%)$ than those who took tincture of maral root. The result in the deadlift of the rod in the control group on the 6th day of the experiment was $169.0 \pm 9.80 \mathrm{~kg}$, and on the 27th day it increased by an average of $1.9 \mathrm{~kg}(170.9 \pm 10.82 \mathrm{~kg})$. In the experimental groups, the positive dynamics was very noticeable: if on the sixth day of the experiment in the first experimental group the indicator was $169.2 \mathrm{~kg}$, then on the 27th day - $180.2 \mathrm{~kg}$ (increase - $11 \mathrm{~kg}$ ). In the experimental group No. 2: on the 6th day of the experiment - $171.10 \mathrm{~kg}$, on the 27 th day $-183.5 \mathrm{~kg}$ (increase - $12.4 \mathrm{~kg}$ ). Note that in this case, the effect of pantocrin on the growth of strength indicators is somewhat stronger than the effect of tincture of maral root. In generalized form, the experimental results can be presented in the following form (Figure 1).

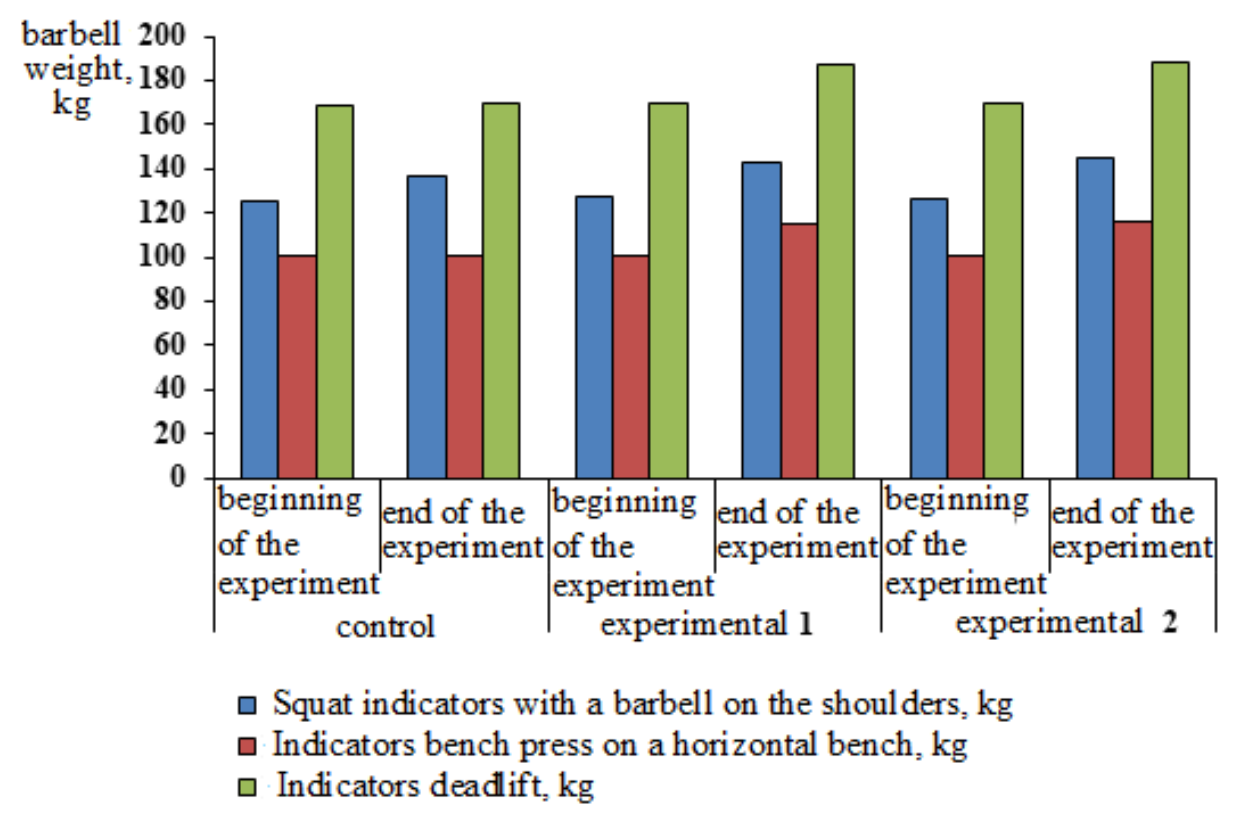

Figure 1. Comparative indicators of the power of powerlifters in the control and experimental groups in a training cycle of 28 days

\section{CONCLUSION}

In a study of the influence of natural adaptotogens - pantocrin and maral root - on the functional state of the body and power indicators of powerlifters, it was found that these drugs help to increase the effectiveness of training sessions (especially muscle strength) and have a positive effect on the cardiovascular system. The positive changes in the morphological composition of the blood of the athletes were revealed: first of all, activation of erythropoiesis and an increase in hemoglobin level. Since the parenteral administration of these adaptogens was carried out against the background of intense physical exertion, we can conclude that they are effective in combination with systematic training loads. Thus, the powerlifting performance in powerlifting over the 28 days of the experiment increased by $12.9 \%$ on adaptogens in squats, $6.6 \%$ in the bench press on the horizontal bench, and $6.9 \%$ in the deadlift. It should be noted that the effect of pantocrin on the adaptive processes of the body is slightly stronger than the maral root. The results obtained in the study when comparing them with other studies of natural adaptogens in sports practice, allow recommending tinctures of pantocrin and maral root for use both in training powerlifters and in other sports. 


\section{REFERENCES}

Abbasi, M., \& Zare, A. (2016). Information Security in E-Commerce Law. UCT Journal of Social Sciences and Humanities Research, 4(3), 16-20.

Aksenov, M.O., \& Andryushchenko, L.B. (2018). Development of power skills of athletes: the role of the myostatin gene. Theory and practice of physical culture, 4, 71-74.

Ayalew, Y. (2017). A Five Circles Model for Designing Mathematics Teacher Education Programs and Framing Common Standards for Educators. International Electronic Journal of Mathematics Education, 12(3), 265-280.

Banting, L. K., Pushkarev, V. P., Cieszczyk, P., Zarebska, A., Maciejewska-Karlowska, A., Sawczuk, M. A., ... \& Pushkareva, Y. E. (2015). Elite athletes' genetic predisposition for altered risk of complex metabolic traits. BMC genomics, 16(1), 25. https://doi.org/10.1186/s12864-014-1199-0

Chesnokov, A.V., \& Fenzel, A.D. (2016). Development of motor skills in technologizing training activities of the student powerlifting team. Theory and practice of physical culture, 6, 61-65.

Gabitov, I.I., Badretdinov, I.D., Mudarisov, S.G., Khasanov, E.R., Lukmanov, R.L., Nasyrov, R.R., Tuktarov, M.F., Atnagulov, D.T., Timeriashev, I.A., \& Pavlenko, V.A. (2018) Modeling the Process of Heap Separation in the Grain Harvester Cleaning System. Journal of Engineering and Applied Sciences, 13, 6517-6526.

Khabibullin, R.M., Ismagilova, E. R., \& Khabibullin, I. M. (2018). Morphological changes of the spleen of mice during exercise and the use of adaptogens. Morphology, 153(3), 289.

Khabibullin, R.M., Ismagilova, E.R., \& Bakirova, A.U. (2018b). Morphology of skeletal muscle tissue in mice during exercise and the use of adaptogens. Morphology. 153(3), 288-289.

Kreider, R., Leutholtz, B., Katch, F., Katch, V. (2009). Exercise and Sport Nutrition. Santa Barbara: Fitness Technologies Press, 5, 53-61.

Ldokova, G.M., Volkova, K.R., Pyanzin, A.I. (2017). Coach's actions in the system of relations coachathlete in powerlifting. Theory and practice of physical culture, 8, 72-74.

Lubova T.N., Islamgulov D.R., Ismagilov K.R., Ismagilov, R.R., Mukhametshin, A.M., Alimgafarov, R.R., Enikiev, R.I., Bakirova, A.U., Kamilanov, A.A.., \& Lebedeva, O.Yu. (2017). Economic Efficiency of Sugar Beet Production. Journal of Engineering and Applied Sciences, 13(8), 6565-6569.

Matsubara, M., \& Yoshida, H. (2018). Fostering autonomous learners of vocabulary acquisition using content-based ict methods. Humanities \& Social Sciences Reviews, 6(1), 36-43. https://doi.org/10.18510/hssr.2018.617

Nikolaev, P.P., \& Nikolaeva, I.V. (2017). Monitoring and modern technologies in the process of organization of classes in power triathlon at the University. Theory and practice of physical culture, $11,89$.

Nikolaev, P.P., \& Nikolaeva, I.V. (2017b). Integral analysis of model morphofunctional characteristics of girls - representatives of mass athletic title in power triathlon. Theory and practice of physical culture, 9, 104.

Ogulchansky, V.A., \& Sedykh, N.V. (2017). Organizing the training process in powerlifting. Theory and practice of physical culture, 7,80 .

Samsonova, A.V., Sheiko, B.I., Kichigina, N.B., \& Samsonov, G.A. (2014). Electrical activity in muscles of the lower extremities when performing bench press. Scientific notes of the University named after P. F. Lesgaft, 5 (111), 159-165.

Samsonova, A.V., Ponomarev, G.N., Tsipin, L.L., \& Bogdanov, O. A. (2018). Biomechanical concept to use power exercises in athlet training. Theory and practice of physical culture, 8, 65-66.

Shafikova, L.R., \& Greb, A.V. (2018). Development of strength skills in students engaged in weightlifting. Theory and practice of physical culture, 6, 45-46. 
Sheiko, B.I., Gorulev, P.S., Rumyantseva, E.R., \& Tsedov, R.A. (2013). Powerlifting. From a beginner to a master. Moscow, pp. 560.

Sheiko, B.I., \& Sarychev, K.I. (2017). Bench press for athletes of all levels of training and physical abilities. Moscow, pp. 523.

Voisin, S., Guilherme, J. P. F., Yan, X., Pushkarev, V. P., Cieszczyk, P., Massidda, M., ... \& Maciejewska, A. (2016). ACVR1B rs2854464 is associated with sprint/power athletic status in a large cohort of Europeans but not Brazilians. PloS one, 11(6). https://doi.org/10.1371/journal.pone.0156316

Yakubenko, Ja. E. (2016). Distribution of training load between separate groups of exercises in powerlifting. Theory and practice of physical culture, 6, 76-78. 